\title{
Evolução da agropecuária em São Paulo e Mato Grosso de 1995 a 2006
}

\author{
Samuel Alex Coelho Campos* \\ Carlos José Caetano Bacha**
}

\section{Resumo}

Este trabalho utiliza alguns conceitos da nova geografia econômica para avaliar as restrições e vantagens que variáveis de primeira e segunda natureza trazem para estimular e/ou restringir a produção agropecuária nos estados de São Paulo e Mato Grosso. Concluise que, apesar de algumas variáveis de segunda natureza (como a legislação florestal) serem potencialmente mais restritivas à agropecuária no Mato Grosso e outras estarem em menor oferta naquele estado, como serviços bancários, de ensino e pesquisa, houve melhora expressiva dessas últimas perspectivas. Isto, juntamente com a grande disponibilidade de terras no estado (com boa topografia e variado clima) mais do que compensou a sua baixa fertilidade. Isto explica alguns indicadores de produtividade parcial mostrarem melhora da agropecuária em Mato Grosso acima dos apresentados em São Paulo entre os anos de 1995 e 2006. Não obstante, não se pode afirmar que a eficiência técnica da agropecuária no Mato Grosso é maior do que em São Paulo, pois nem todas as variáveis consideradas no cálculo dessa eficiência foram analisadas no artigo.

Palavras-chave: Agropecuária. Mato Grosso. São Paulo. Evolução.

* Professor adjunto na Universidade Federal Fluminense. E-mail: s.alex.coelho@gmail.com

** Professor titular na Escola Superior de Agricultura Luiz de Queiroz, Universidade de São Paulo. E-mail: carlosbacha@usp.br

http://dx.doi.org/10.5335/rtee.v22i46.6751

Submissão: 04/05/2016. Aceite: 10/06/2016. 


\section{Introdução}

A nova geografia econômica (NGE) - ver Krugman (1998) e Fujita e Krugman (2004) - analisa a concentração de atividades econômicas em certa região, destacando as chamadas forças centrípetas e centrífugas determinantes da concentração, ressaltando como variáveis de primeira e segunda natureza associam-se a essas forças. Tradicionalmente, São Paulo contou com forças centrípetas, tais como concentração de centros de pesquisas e ensino na agropecuária, redes de transporte ligando municípios produtores e consumidores/exportadores, rede bancária, de comércio e de serviços e, até a década de 1960, com a possibilidade de incorporar novas áreas à produção agropecuária. Isso explica o fato de o valor da produção agropecuária de São Paulo em 1970 ter representado 20,8\% da produção agropecuária do Brasil. No entanto, São Paulo tem perdido importância dentro da agropecuária nacional, ainda que se mantenha importante. Em 2006, São Paulo representou 17,2\% do valor da produção agropecuária nacional (IBGE,1998; 2009).

De outro lado, Mato Grosso só passa a ter maior destaque na agropecuária nacional a partir da década de 1970, à medida que variáveis de segunda natureza (como ampliação da rede bancária, de comércio e serviços, infraestrutura de transporte e centros de pesquisa e ensino, por exemplo) ampliam sua disponibilidade no Estado, permitindo à agropecuária crescer com a ampla disponibilidade de terras existentes. Em 1970, Mato Grosso representou 3,2\% do valor bruto da produção agropecuária do Brasil, e, em 2006, 7,5\%. No entanto, a legislação florestal é mais restritiva sobre Mato Grosso do que em São Paulo.

Considerando o contexto supracitado, o objetivo geral deste artigo é analisar e comparar algumas variáveis de primeira e segunda natureza que levam ao crescimento relativamente mais acelerado da agropecuária em Mato Grosso do que em São Paulo de 1970 a 2006 e ressaltar as diferenças das estruturas produtivas da agropecuária desses dois estados. A análise restringe-se até o ano de 2006, devido a esse ser o ano do último censo agropecuário existente, cujos dados são essenciais para elaborar o presente artigo.

Há ampla literatura analisando a agropecuária paulista, destacando as condições edafoclimáticas que levaram ao crescimento da cafeicultura e de outras atividades no estado (ARAÚJO et al., 2003; MANZATTO et al., 2009; FUNDAÇÃO SISTEMA ESTADUAL DE ANÁLISE DE DADOS, 2003), sua rede de serviços (CANO et al., 2007) e a divisão geográfica da agropecuária existente dentro do estado (MARTIN, 1993; TSUNECHIRO et al., 2001). Ainda que menor, mas não menos expressiva, entre a literatura abordando a agropecuária de Mato Grosso 
destacam-se Bonjour, Figueiredo e Marta (2008), Figueiredo, Barros e Guilhoto (2005), Pereira (2007) e Sicsú e Lima (2000). Essa literatura não analisa os fatores causadores da expansão agropecuária nos estados citados sob a ótica da nova geografia econômica, em especial, separando variáveis de primeira e segunda natureza, como pretende fazer o presente artigo.

Inicialmente, o modelo teórico da nova geografia econômica é apresentado (ver item 2), posteriormente, as características edafoclimáticas de cada estado são apresentadas e comparadas (item 3). A seguir, a presença do Estado por meio da legislação florestal, a infraestrutura de transportes disponível no estado, a educação e a rede bancária (incluindo a privada) são apresentadas (item 4). Após, as características e a evolução da agropecuária em cada estado analisado (São Paulo e Mato Grosso) são descritas, confrontadas e interligadas às características edafoclimáticas e à atuação do poder público (em especial, o federal) em cada um desses estados (item 5). Por fim, as conclusões são apresentadas no item 6.

\section{Referencial analítico e dados utilizados}

Este artigo parte de alguns conceitos da nova geografia econômica (expostos no item 2.1) para explicar o processo de desenvolvimento da agropecuária nos dois estados analisados. Em seguida, selecionam-se algumas variáveis, disponíveis e comparáveis no mesmo momento do tempo, para ambos estados e coerentes com as propostas da NGE (item 2.2).

\subsection{A nova geografia econômica}

A nova geografia econômica busca explicar a distribuição das atividades econômicas no espaço por meio da interação de duas forças, a centrípeta, que levaria à concentração das atividades, e a centrífuga, que levaria à dispersão. Como exemplos de variáveis de força centrípeta pode-se citar o potencial de mercado e a infraestrutura de transporte (SILVA; BACHA, 2014), transbordamentos do tamanho do mercado, densidade do mercado de trabalho e economias externas puras (Krugman, 1998), bem como solos de maior fertilidade natural e relevo e clima mais favoráveis à agropecuária. Por outro lado, fatores imóveis e deseconomias de escalas puras tendem a agir como forças centrífugas, dispersando as atividades no espaço.

As variáveis associadas à concentração das atividades produtivas no espaço podem ser classificadas como de: i) primeira natureza, que são aquelas que decorrem 
das condições naturais da região onde a firma está localizada (SCHMUTZLER, 1999); ii) segunda natureza, como o potencial de mercado, densidade do mercado de trabalho e economias externas puras (SILVA; BACHA, 2014).

Dessa forma, mesmo regiões que não apresentam condições naturais favoráveis podem apresentar concentração de atividades produtivas. Isso pode ser explicado por um processo de retroalimentação. Segundo Schmutzler (1999), uma vez que uma região alcança um elevado percentual da produção total, ela torna-se atraente para empresas pelo fato de que muitas empresas já estão localizadas naquele espaço (e não por causa da dotação de recursos). Essa concentração de agentes produtivos leva a retornos crescentes de escala, à redução do custo de transporte dos insumos e da produção à medida que produtores e consumidores (tanto finais como intermediários) se concentram, e à concentração de fatores produtivos móveis (como mão de obra). Esse aumento da densidade da mão de obra aumenta a demanda, e também leva a melhorias nas possibilidades de consumo.

Esse crescimento da produção em um polo também pode incentivar a adoção de políticas públicas de apoio ou incentivo à produção. Assim, esse processo leva à retroalimentação. Esses fatores podem ser classificados como forças centrípetas, na medida em que agem como forças de atração, favorecendo a concentração das atividades produtivas. Contrário a essa força, têm-se as forças centrífugas (KRUGMAN, 1998) que tendem a promover a dispersão das atividades agropecuárias e advêm essencialmente da imobilidade da produção agropecuária, que é dependente da terra. Ademais, a concentração de atividades econômicas pode aumentar a demanda por insumos (terra, mão de obra e capital), elevar o seu custo. Como a terra não pode ser criada, o aumento da concentração da produção agropecuária aumenta a demanda por novas áreas, valorizando cada vez mais as áreas restantes que poderiam ser utilizadas na produção agropecuária, aumenta seu custo de aquisição e/ou o valor do seu aluguel. A produção agropecuária tenderia a deslocar para outras áreas (de fronteira agrícola) mais baratas. Comportamento semelhante ocorre com a mão de obra, uma vez que à medida que a produção agropecuária aumenta, aumenta a demanda por mão de obra naquela área, o que aumenta o seu custo e, novamente, a produção agropecuária se desloca em busca de novas áreas com mão de obra mais barata. Ademais, a elevada concentração da produção agropecuária pode ocasionar deseconomias de escala, como a capacidade de armazenamento da produção insuficiente na região, desgaste das estradas pelo fluxo intenso de caminhões para escoar a produção, entre outros problemas. 


\subsection{Fonte e tratamento dos dados}

Esta seção descreve as variáveis utilizadas e a fonte de dados que foram utilizadas nas seções subsequentes para explicar a dinâmica da produção agropecuária: ou seja, descrever quais os fatores que levam ao crescimento relativamente mais acelerado da agropecuária em Mato Grosso do que em São Paulo de 1970 a 2006 e ressaltar as diferenças das estruturas produtivas da agropecuária desses dois estados.

As variáveis foram divididas em duas tabelas. A Tabela 1 apresenta as variáveis de primeira e segunda natureza, sua unidade bem como sua fonte.

Tabela 1 - Variáveis de forças centrípetas e centrífugas quanto à natureza

\begin{tabular}{|c|c|c|c|}
\hline Variável & Unidade & Fonte & Natureza \\
\hline Fertilidade do solo & - & $\begin{array}{l}\text { Instituto Brasileiro de Geografia e } \\
\text { Estatística (IBGE) }\end{array}$ & $1 \underline{a}$ \\
\hline Relevo & - & IBGE & 1 a \\
\hline Clima & - & IBGE & $1 \underline{a}$ \\
\hline Bioma & - & IBGE & $1 \underline{a}$ \\
\hline $\begin{array}{l}\text { Rodovias pavimentadas e não } \\
\text { pavimentadas }\end{array}$ & $\mathrm{km}$ & $\begin{array}{l}\text { Departamento Nacional de } \\
\text { Infraestrutura de Transportes }\end{array}$ & $2^{\mathrm{a}}$ \\
\hline Capacidade de armazenamento & ton. & $\begin{array}{l}\text { Companhia Nacional de } \\
\text { Abastecimento }\end{array}$ & $2^{\mathrm{a}}$ \\
\hline $\begin{array}{l}\text { Cursos na área de ciências agrárias } \\
\text { e alunos matriculados }\end{array}$ & unid. & $\begin{array}{l}\text { Instituto Nacional de Estudos e } \\
\text { Pesquisas Educacionais Anísio } \\
\text { Teixeira }\end{array}$ & $2^{a}$ \\
\hline Agências bancárias & unid. & Banco Central & $2^{\mathrm{a}}$ \\
\hline Crédito rural & $\mathrm{R} \$$ & Banco Central & $2^{a}$ \\
\hline
\end{tabular}

Fonte: elaborada pelos autores com base nas informações disponíveis nas fontes citadas.

A Tabela 2 apresenta as variáveis analisadas e confrontadas entre os estados de forma a explicar as causas do crescimento relativamente mais acelerado da agropecuária em Mato Grosso do que em São Paulo, de 1995 a 2006, e ressaltar as diferenças das estruturas produtivas da agropecuária desses dois estados, tomando como causas as variáveis de forças centrífugas e centrípetas (ver Tabela 1) 
Tabela 2 - Variáveis da produção agropecuária comparadas entre os estados

\begin{tabular}{l|c|c}
\hline \multicolumn{1}{c|}{ Variável } & Unidade & \multicolumn{1}{c}{ Fonte } \\
\hline Valor da produção agropecuária, por atividade & $\mathrm{R} \$$ & IBGE - censo agropecuário \\
Número de estabelecimentos & unid. & IBGE - censo agropecuário \\
Área dos estabelecimentos & ha & IBGE - censo agropecuário \\
Área média dos estabelecimentos & ha & IBGE - censo agropecuário \\
Área utilizada, por utilização das terras ${ }^{1}$ & ha & IBGE - censo agropecuário \\
Pessoal ocupado & unid. & IBGE - censo agropecuário \\
Tratores & unid. & IBGE - censo agropecuário \\
Bovinos & cabeças & IBGE - censo agropecuário \\
Financiamento & $R \$$ & IBGE - censo agropecuário \\
Investimento & $R \$$ & IBGE - censo agropecuário \\
Despesas com defensivos & $R \$$ & IBGE - censo agropecuário \\
\hline
\end{tabular}

Fonte: elaborada pelos autores com base nas informações disponíveis nas fontes citadas.

Nota 1: São os grupos de utilização: lavouras permanentes, lavouras temporárias, pastagens naturais, pastagens plantadas, matas naturais e matas plantadas.

Assim, os dados são secundários, obtidos com os diversos órgãos de pesquisa brasileiros. O período de análise concentra-se nos anos entre 1995/1996 e 2006, embora tenha sido analisada a trajetória de evolução de algumas variáveis, de 1994 a 2014, como o volume disponibilizado do crédito rural, por exemplo, o que permitiu explicar e comparar o crescimento da agropecuária do Mato Grosso em relação ao estado de São Paulo. $\mathrm{O}$ foco do ano de análise deve-se à disponibilidade dos dados, principalmente quando se considera o censo agropecuário, cujos últimos dados são dos anos 1995/96 a 2006.

\section{Características edafoclimáticas de São Paulo e Mato Grosso}

A produção agropecuária tem estreita dependência do meio ambiente (solo, clima, relevo, temperatura, entre outros aspectos), uma vez que é ele que determina o tipo de produto possível na produção agropecuária, os diversos sistemas de produção que podem ser adotados (MARTIN, 1993) e influi diretamente na produtividade, qualidade e forma com que os insumos serão alocados.

A produção agropecuária é favorecida no estado do Mato Grosso pelo seu relevo predominantemente plano e suave ondulado (com $3 \%$ a $8 \%$ de declividade) - o 
que facilita a mecanização das atividades agropecuárias - e por apresentar uma temperatura mínima média de $17^{\circ} \mathrm{C}$, nas regiões de clima tropical de altitude, e máxima média de $32^{\circ} \mathrm{C}$ no tropical do Pantanal (FERREIRA, 2001). O estado apresenta, entretanto, maior nível de $\mathrm{pH}$ no solo, mas que pode ser facilmente corrigido.

No estado de São Paulo, a atenção deve ser dada para as áreas com declividade acima de $12 \%$, que inviabilizam a colheita mecânica da cana (MANZATTO et al., 2009). O relevo desse estado é plano e suave ondulado a oeste. À medida que se desloca para leste, o relevo se torna ondulado ( $8 \%$ a $20 \%$ de declividade) e montanhoso. A quase totalidade do estado insere-se na zona climática tropical Brasil Central e uma pequena porção está na zona de clima temperado (INSTITUTO BRASILEIRO DE GEOGRAFIA E ESTATÍSTICA, 2012). Essas condições edafoclimáticas limitam, em várias áreas do estado de São Paulo, a cultura mecanizada de grãos, mas favorece o plantio de culturas perenes (cafeeiros, laranjeiras e eucaliptos) ou semiperenes (como a cana-de-açúcar).

Considerando-se os biomas, no estado do Mato Grosso podem ser encontrados os biomas Amazônico (54\% da superfície do estado), Cerrado (39\%) e Pantanal (7\%), enquanto que no estado de São Paulo podem ser encontrados o bioma Cerrado e Mata Atlântica, correspondendo a $32 \%$ e $68 \%$, respectivamente, do seu território (IBGE, 2004). O mérito em considerar o bioma está na sua definição ampla, que incorpora as condições físicas predominantes (clima, geomorfologia, pedologia, etc.), a vegetação e a biodiversidade.

No estado do Mato Grosso, o bioma Pantanal apresenta algumas limitações para a exploração agropecuária. Segundo dados de Brasil (2010) e IBGE (2012), a produção agrícola é desaconselhável nessa área devido às enchentes periódicas e aos solos pouco férteis. Essas características fazem com que a pecuária extensiva seja predominante. Ademais, a Lei n⿳o 8.830/2008 (MATO GROSSO, 2008), no seu artigo $9^{\circ}$, proíbe a implantação de projetos agrícolas, exceto a atividade agrícola de subsistência e a pecuária extensiva, na planície alagável da Bacia do Alto Paraguai do Mato Grosso.

Analisando os solos e sua potencialidade agrícola em cada estado (fertilidade do solo e as características físicas e morfológicas), constata-se que a maior parte do estado do Mato Grosso apresenta baixa fertilidade, com baixa disponibilidade de nutrientes e excesso de alumínio, mas com boas características físicas e relevo plano a suave ondulado (IBGE, 2012). Assim, segundo Castro (2014), para que a produção agropecuária apresente boa produtividade, os solos da região necessitam de adubação, para melhorar a fertilidade do solo, e aplicação de calcário, para reduzir a acidez do solo, melhorar a disponibilidade dos nutrientes e reduzir 
a concentração do alumínio. Ao sul do estado, a maior proporção das áreas é desaconselhável à prática agrícola devido à sua fertilidade ser muito baixa, haver alta salinidade, reduzida profundidade do solo, presença de pedregosidade ou rochosidade e textura arenosa (BRASIL, 2010; IBGE, 2012).

O estado de São Paulo, por sua vez, apresenta solos de baixa disponibilidade de nutrientes e excesso de alumínio na região dos Cerrados, solos com elevada potencialidade agrícola no oeste e potencialidade regular no leste, devido ao seu relevo montanhoso e aos declives acentuados da Serra do Mar, restrições de drenagem e excesso de alumínio (IBGE, 2012).

Do acima exposto, conclui-se que o relevo permite o uso de máquinas e implementos na quase totalidade dos dois estados analisados, exceção da parte Sul no Mato Grosso (área do Pantanal) e na porção leste de São Paulo (na Serra do Mar). Ambos os estados demandam o uso de calcário e fertilizantes para que a produção agropecuária alcance boa produtividade, embora algumas áreas no estado de São Paulo apresentem maior fertilidade natural, o que reduz a quantidade necessária de fertilizantes e de calcário para que a produção agropecuária tenha boa produtividade.

Essas diferenças das características edafoclimáticas (que são variáveis de primeira natureza, segundo a NGE) entre cada estado e entre seus municípios determinam o potencial agrícola, a gama de atividades, ora limitando as atividades ora permitindo a diversificação e dinamismo da produção agropecuária.

\section{Presença do Estado, legislação ambiental e atividades de apoio à produção agropecuária}

Este item descreve e discute brevemente a presença do Estado na produção agropecuária, ora restringindo as ações dos produtores agropecuários (por meio da legislação, principalmente por meio do Código Florestal), ora apoiando a produção agropecuária por meio da construção de infraestrutura de transportes e armazenagem, de logística de comercialização, oferecendo serviços de educação, crédito rural e a rede bancária. Procura-se mostrar como essa atuação, que afeta variáveis de segunda natureza, tem sido diferente sobre São Paulo e Mato Grosso. 


\subsection{Legislação}

A produção agropecuária está sujeita a diversas legislações (nas formas de leis, decretos e instruções normativas, por exemplo) que restringem e/ou disciplinam essa atividade. Dentre as leis e outras regulações às quais a agropecuária está sujeita, o Código Florestal (BRASIL, 2012b) apresenta destaque por determinar áreas dentro dos estabelecimentos agropecuários que têm uso restrito ou proibido, que são as áreas de reserva legal, áareas de preservação permanente (APPs) e as áreas de uso restrito. Essa última foi criada no novo Código Florestal, Lei no 12.651 , de 25 de maio de 2012 (BRASIL, 2012b) e modificada pela Lei no ${ }^{2} 2.727$, de 17 de outubro de 2012. Foram classificadas como áreas de uso restrito, os pantanais e as planícies pantaneiras, onde foi permitida a exploração ecologicamente sustentável, desde que atendendo a normas técnicas oficiais, e com inclinação entre $25^{\circ}$ e $45^{\circ}$.

O novo Código Florestal substituiu o código anterior, de 1965, e suas alterações (Lei $n^{\circ}$ 4.771/1965) apresentando algumas mudanças em relação ao último. Uma das principais modificações do novo Código Florestal é a criação da área consolidada, definida como "área de imóvel rural com ocupação antrópica preexistente a 22 de julho de 2008, com edificações, benfeitorias ou atividades agrossilvipastoris, admitida, neste último caso, a adoção do regime de pousio" (BRASIL, 2012b, p. 16).

Outro ponto importante foi a criação do Cadastro Ambiental Rural (CAR). Esse é um registro eletrônico de âmbito nacional e obrigatório para todos os imóveis rurais. O CAR é um mecanismo encontrado para a regularização das propriedades que estavam inadequadas conforme a lei florestal anterior, sendo que a inscrição nesse cadastro permite que os produtores façam a adesão ao Programa de Regularização Ambiental. Assim, a criação do CAR permite diversos benefícios aos produtores rurais, como a regularização de áreas de preservação permanente e da reserva legal alteradas até 22 de julho de 2008 no imóvel rural e a suspensão de sanções pelo uso irregular até 22 de julho de 2008 de APPs, reserva legal e áreas de uso restrito.

Foi criado o Programa de Apoio e Incentivo à Conservação do Meio Ambiente por meio da Lei no 12.651 , de 25 de maio de 2012, que permite que o governo federal apoie e incentive a conservação do meio ambiente e a adoção de tecnologias e boas práticas que reduzam os impactos ambientais por meio de pagamentos a serviços ambientais ou incentivos fiscais. Estão incluídos nesse programa, o sequestro de carbono, a conservação da beleza cênica, a biodiversidade das águas e dos serviços hídricos, a regulação do clima, entre outros itens. Esse programa também instituiu a Cota de Reserva Ambiental, que é um título que representa a área com vegetação 
nativa, existente ou em processo de recuperação sob regime de servidão ambiental e que corresponde à área da reserva legal que excede aos percentuais mínimos exigidos conforme o novo Código Florestal e que pode ser comprada por aqueles produtores que apresentam déficit na área da reserva legal no seu estabelecimento agropecuário, como forma de compensar esse déficit.

Cabe destacar que o novo Código Florestal não modificou os percentuais mínimos da lei anterior (Lei n⿳ ${ }^{\circ}$ 4.771/1965 e suas modificações) estipulados para a reserva legal, de forma que estabelecimentos rurais localizados na Amazônia Legal (na qual está inserida parte do Mato Grosso) devem manter $80 \%, 35 \%$ ou $20 \%$ de sua área total com reserva legal se o imóvel estiver situado em área de florestas, cerrado e campos gerais, respectivamente. Para as demais regiões do país (como em São Paulo), o percentual mínimo da área total a ser mantida como reserva legal também continuou fixado em $20 \%$ da área total do imóvel rural.

As normas do Código Florestal, uma vez implementadas, impactam mais negativamente a produção agropecuária no Mato Grosso do que em São Paulo, pois o primeiro estado está sujeito a maiores percentuais de reserva legal do que o segundo e tem menos áreas desmatadas consideradas no perdão de reposição da reserva legal.

\subsection{Infraestruturas}

As infraestruturas de transportes em São Paulo e Mato Grosso apresentam algumas diferenças importantes. Esse é um fator de maior restrição no estado do Mato Grosso devido à grande produção agropecuária, à distância do mercado consumidor e dos portos e às condições precárias das rodovias, principal meio de escoamento da produção agropecuária do Mato Grosso.

Considerando as rodovias, o estado do Mato Grosso mesmo com uma área de $903.366,192 \mathrm{~km}^{2}$ (IBGE, 2014), tinha apenas 40.778,6 $\mathrm{km}$ de rodovias, apenas $18 \%$ delas eram pavimentadas em 2013 (DEPARTAMENTO NACIONAL DE INFRAESTRUTURA DE TRANSPORTES, 2013a). Enquanto isso, o estado de São Paulo contava com 195.405,3 $\mathrm{km}$ de rodovias, sendo que $15 \%$ delas eram pavimentadas (DEPARTAMENTO NACIONAL DE INFRAESTRUTURA DE TRANSPORTES, 2013b). Assim, o primeiro estado citado tem uma densidade de rodovias, em quilômetros, por quilômetros quadrados da área total do estado, de apenas $0,045 \mathrm{~km} /$ $\mathrm{km}^{2}$, enquanto o segundo, $0,787 \mathrm{~km} / \mathrm{km}^{2}$.

A elevada proporção de rodovias não pavimentadas é um problema maior no estado do Mato Grosso, onde 68,3\% e 4,5\% das rodovias não pavimentadas são 
estaduais e federais (DEPARTAMENTO NACIONAL DE INFRAESTRUTURA DE TRANSPORTES, 2013a), respectivamente. São as rodovias com jurisdição estadual ou federal as mais necessárias para o escoamento da produção agropecuária do Mato Grosso para o restante do país ou para exportação. Para o estado de São Paulo, apesar da baixa proporção das rodovias pavimentadas, a maior parte das não pavimentadas são de jurisdição municipal, equivalente a 99,3\% do total de rodovias paulistas não pavimentadas (DEPARTAMENTO NACIONAL DE INFRAESTRUTURA DE TRANSPORTES, 2013b).

Quanto às ferrovias, segundo dados da Agência Nacional de Transportes Terrestres(2009), a extensão das principais linhas e ramais da rede ferroviária concedidas em 2008 compreendia apenas 104 quilômetros no estado do Mato Grosso, enquanto em São Paulo alcançava $4.706 \mathrm{~km}$, sendo a segunda maior extensão do país, perdendo apenas para Minas Gerais.

Ademais, quando se considera a baixa capacidade de armazenamento da produção no território mato-grossense, a infraestrutura de transportes assume maior importância, haja vista que a produção deve ser escoada rapidamente após a colheita da produção para os centros consumidores. Verifica-se que a maior capacidade de armazenamento de grãos no Mato Grosso concentra-se no centro do estado, que também é a região com maior densidade rodoviária (Figura 1) e com maior produção de grãos.

Figura 1 - Rodovias estaduais e federais, hidrovias e capacidade estática de armazenamento (fevereiro de 2016), Mato Grosso

Legenda

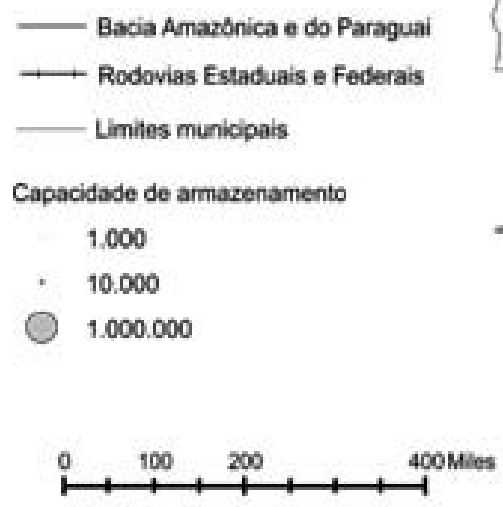

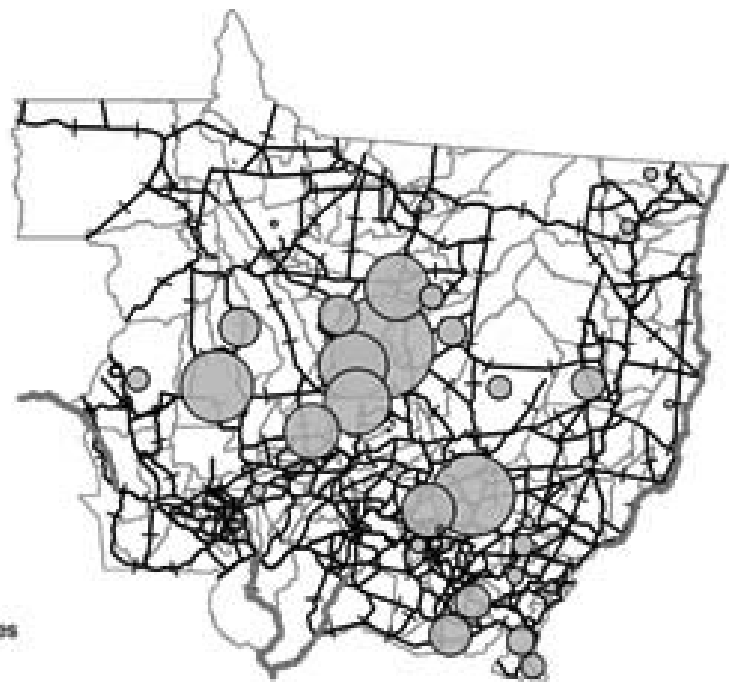

Fonte: elaborada pelo autor com dados de BRASIL (2008) e COMPANHIA NACIONAL DE ABASTECIMENTO (2016b). 
Entretanto, há um descompasso entre a capacidade de armazenamento e produção, que pode ser percebido quando se compara a capacidade estática de armazenamento da Companhia Nacional de Abastecimento (Conab) e a produção estimada no Mato Grosso. Em fevereiro de 2016, a capacidade estática de armazenamento cadastrada na Conab era 32.908 mil toneladas (COMPANHIA NACIONAL DE ABASTECIMENTO, 2016b), enquanto a produção de cereais estimada no Mato Grosso para a safra 2015/2016 é de 50.603,2 mil toneladas ${ }^{1}$ (COMPANHIA NACIONAL DE ABASTECIMENTO, 2016). A baixa capacidade de armazenamento da produção agrícola leva o sistema de transporte ao colapso na época da safra, já que a maior parte da produção deve ser escoada devido à sua perecibilidade e/ou escassez de armazenagem (MENDES; PADILHA JÚNIOR, 2007).

O estado de São Paulo, por sua vez, tem uma produção de grãos estimada de 7.746,0 mil toneladas (COMPANHIA NACIONAL DE ABASTECIMENTO, 2016b) e uma capacidade estática total de armazenamento cadastrada de 11.595,8 mil toneladas em fevereiro de 2016 (COMPANHIA NACIONAL DE ABASTECIMENTO, 2016). Assim, o estado de São Paulo não possui problemas semelhantes ao do Mato Grosso na rede de transporte e armazenagem, principalmente, quando se considera que naquele estado localiza-se o porto de Santos - um dos principais portos utilizados para as exportações de produtos agrícolas do Brasil. Analisando-se apenas as exportações de soja (em grão e farelo) até dezembro de 2015, esse porto movimentou 17.429,5 mil toneladas (COMPANHIA DOCAS DO ESTADO DE SÃO PAULO, 2015).

\subsection{Cursos de ciências agrárias e instituições de pesquisa}

A presença de instituições de ensino ligadas à área agrária pode apresentar o efeito de difusão de novas tecnologias e a consequente melhoria de produtividade sobre os produtores agropecuários dos municípios vizinhos. É razoável supor que quanto maior for o número de cursos e alunos matriculados na área de ciências agrárias em uma dada instituição, maior deve ser o efeito dessa instituição de ensino sobre os ganhos de produtividade, adoção de novas tecnologias, bem como o uso de técnicas de produção adequadas no município em que ela está instalada e sobre os municípios vizinhos.

Entre 1995 e 2006, o estado do Mato Grosso apresentou substancial elevação no número de cursos presenciais na área de ciências agrárias e no número de alunos matriculados. Em 1995, esse estado contava com 676 alunos matriculados e apenas três cursos na área em apreço (agronomia, engenharia florestal e medicina 
veterinária). Em 2006, o estado contava com 31 cursos em ciências agrárias e 3.764 alunos matriculados (INSTITUTO NACIONAL DE ESTUDOS E PESQUISAS EDUCACIONAIS ANÍSIO TEIXEIRA, 2008). Dentre os cursos, destaca-se a preocupação com a gestão do agronegócio, setor responsável por elevada parcela do produto interno bruto (PIB) do Mato Grosso, ${ }^{2}$ sendo que somente entre 2003 e 2006 foram criados quatro cursos.

O estado de São Paulo, por outro lado, contava com 38 cursos na área de ciências agrárias e um total de 10.195 alunos matriculados em 1995, enquanto que em 2006 eram 19.889 alunos matriculados em 86 cursos. Nesse estado também foram criados alguns cursos considerados "novos", como três cursos que tratam da gestão de agronegócios e quatro cursos voltados especificamente para a produção sucroalcooleira, reflexo da importância que a produção de cana apresenta para São Paulo. Além desses, foram criados novos cursos de medicina veterinária, gestão ambiental, agronomia e zootecnia.

Dentre os órgãos públicos de pesquisa agropecuária no estado de São Paulo, podem ser destacadas as três universidades estaduais (com seus programas de pós-graduação), a Embrapa Instrumentação, a Embrapa Monitoramento por Satélite, a Embrapa Meio Ambiente, a Agência Paulista de Tecnologia Agropecuária e o Instituto Agronômico de Campinas. No Mato Grosso, pode-se destacar a unidade da Embrapa Agrossilvipastoril, criada em 7 de maio de 2009 e inaugurada em julho de 2012, bem como o Instituto Mato-Grossense de Economia Agropecuária, a Universidade Federal do Mato Grosso e a Universidade Estadual do Mato Grosso.

Em termos de estrutura de ensino e pesquisa em ciências agrárias, São Paulo conta com maior disponibilidade do que o Mato Grosso, mas o salto observado quanto a esse aspecto no estado do Centro-Oeste é muito elevado e há desconcentração desse serviço no Brasil.

\subsection{Rede bancária e crédito rural}

O crédito rural tem um papel importante para incentivar a produção agropecuária, haja vista que o produtor agropecuário se depara com riscos elevados de preços e de produtividade - advindos de pragas, doenças e condições do clima (BACHA, 2012). Nesse sentido, o número de agências bancárias e o número de municípios com unidades bancárias podem ser considerados como um facilitador na obtenção do crédito rural, bem como na comercialização da produção.

A comparação entre o número de agências nos estados de Mato Grosso e São Paulo (Figuras 2 e 3) indica que o segundo apresenta número maior de unidades.. 
Entretanto, São Paulo também apresenta um número maior de municípios, assim, quando se compara o número de municípios com o de agências bancárias, o percentual não apresenta diferença significativa. No ano de 1995, São Paulo e Mato Grosso tinham agências bancárias em $64 \%$ e $54 \%$ dos municípios, respectivamente, sendo que esses percentuais aumentaram para $66 \%$ e $57 \%$ em 2006 , respectivamente.

Figura 2 - Número de agências bancárias e valor do crédito rural, em bilhões de reais em julho de 2014, Mato Grosso

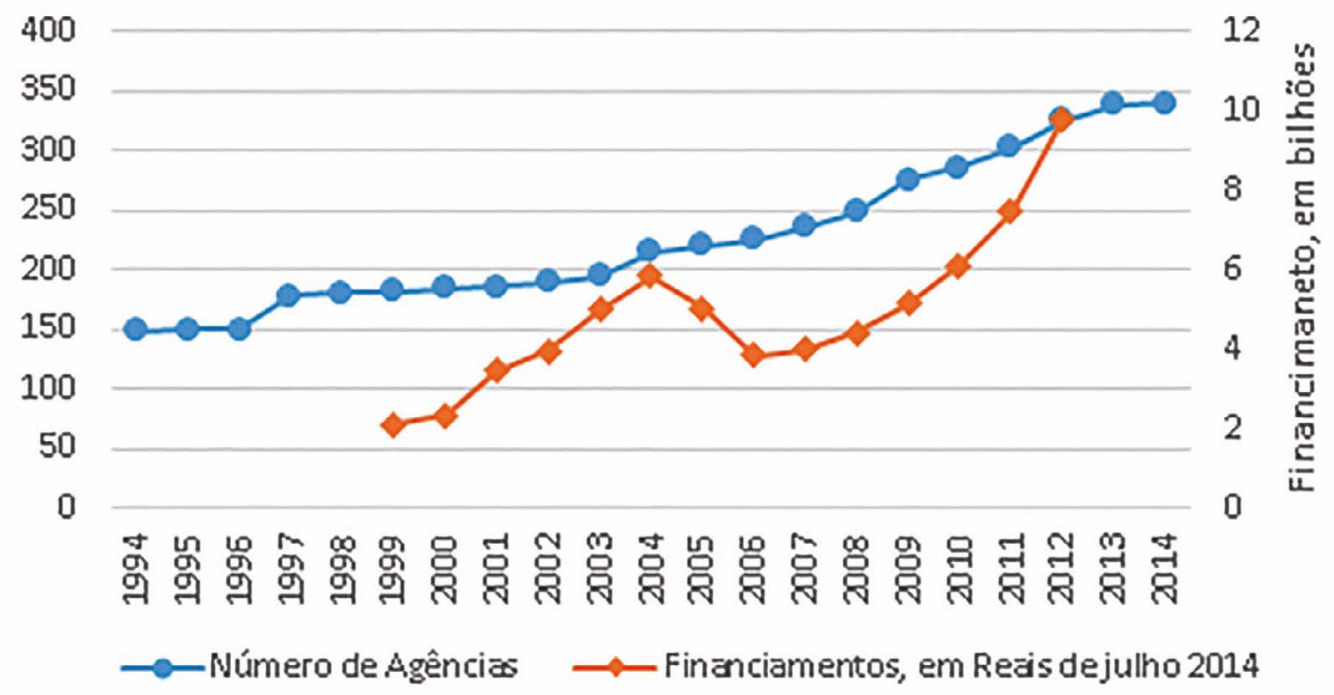

Fonte: Banco Central do Brasil (BRASIL, 2012; 2014).

Nota 1: Os valores do crédito rural incuem financiamentos concedidos a produtores e cooperativas.

Nota 2: Foi utilizado o Indice Geral de Preços - Disponibilidade Interna (FUNDAÇÃO GETÚLIO VARGAS, 2014) para o deflacionamento.

Mesmo que a diferença do número de municípios com agências seja pequena, a disparidade no valor do crédito rural entre os estados é substancial. Por exemplo, em 2012, o valor concedido à produção agropecuária no estado do Mato Grosso foi de $R \$ 9$ bilhões, enquanto São Paulo recebeu $R \$ 16$ bilhões (em Reais de julho de 2014). Quando se analisa o financiamento concedido por finalidade (custeio, investimento e comercialização), a diferença no montante do crédito desses estados deve-se ao valor financiado como custeio e comercialização. Tomando 2012 como exemplo, novamente, o valor financiado com custeio e comercialização em São Paulo foi de $\mathrm{R} \$ 9$ bilhões e $\mathrm{R} \$ 3$ bilhões, em reais de julho de 2014, respectivamente. Por outro lado, o estado do Mato Grosso obteve $\mathrm{R} \$ 5$ bilhões e $\mathrm{R} \$ 962$ milhões, em 
reais de julho de 2014, para financiamento com custeio e comercialização, respectivamente. Esse viés no Mato Grosso para obtenção de crédito de custeio pode comprometer a produtividade agropecuária e ganhos de eficiência, quando comparado a São Paulo.

Figura 3 - Número de agências bancárias e valor do crédito rural, em bilhões de reais de 2013, São Paulo

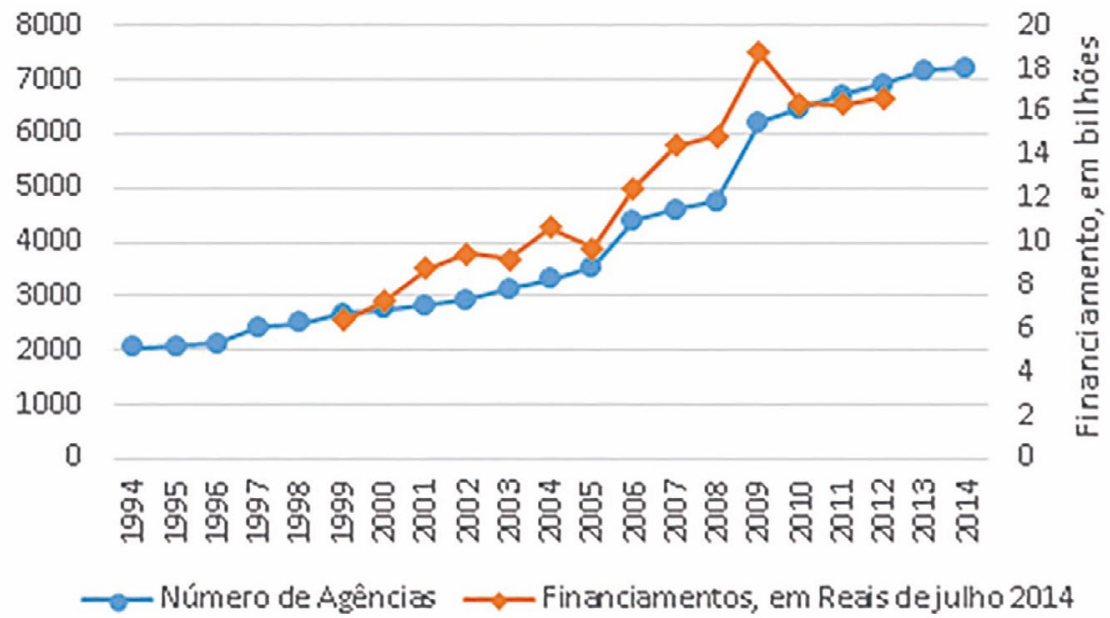

Fonte: Banco Central do Brasil (BRASIL, 2012; 2014).

Nota 1; Os valores do crédito rural incluem financiamentos concedidos a produtores e cooperativas.

Nota 2: Foi utilizado o Indice Geral de Preços - Disponibilidade Interna (FUNDAÇÃO GETÚLIO VARGA, 2014) para o deflacionamento.

Assim, as variáveis de segunda natureza (legislação florestal, infraestrutura, ensino e pesquisa e crédito) favorecem a produção agropecuária em São Paulo, mas o expressivo incremento e melhora dessas variáveis no Mato Grosso permite, em tese, um crescimento mais expressivo da produção agropecuária, em especial, se for considerado que Mato Grosso ainda tem áreas a serem utilizadas.

\section{Produção agropecuária}

Mato Grosso apresenta uma economia mais dependente da produção agropecuária quando comparado ao estado de São Paulo. Essa importância da agropecuária pode ser observada por meio da representatividade da agropecuária sobre o PIB total estadual. Entre 1995 e 2009, a agropecuária representou, em média, 22\% e 
$3 \%$ do valor total do PIB estadual do Mato Grosso e de São Paulo, respectivamente (INSTITUTO DE PESQUISA ECONÔMICA APLICADA, 200-).

A diferença desses estados quanto à importância das atividades agropecuárias para a economia deve-se à forma e ao período de ocupação do território, além das condições de infraestrutura e condições edafoclimáticas. No período anterior ao desenvolvimento da cafeicultura, a agricultura paulista era rudimentar, predominantemente voltada para a subsistência. Isso se devia ao fato da cultura da cana de açúcar não ter se adaptado bem às condições edafoclimáticas do estado na época colonial e à competição da produção do Nordeste, mais próxima dos mercados consumidores (ARAÚJO et al., 2003). No século XIX, a cultura cafeeira expandiu-se no estado de São Paulo, inicialmente no Vale do Paraíba e, posteriormente, no Oeste paulista. Ademais, essa cultura não demandava áreas planas para o seu cultivo. Segundo Nicholls (1970), essa expansão da cafeicultura para o Oeste paulista, resultado da busca por solos virgens, permitiu a colonização e o desenvolvimento de boa parte do estado, completando sua colonização em 1935.

A cultura do café trouxe benefícios para a economia do estado de São Paulo, uma vez que o deslocamento dessa cultura para o Oeste paulista incentivou a construção de ferrovias e rodovias, infraestrutura de comunicação e serviços bancários e também incentivou a diversificação e desenvolvimento de outras culturas, muitas das quais eram cultivadas entre as plantações do café. A cultura cafeeira demandava considerável mão de obra na colheita, e o cultivo intercalar era uma estratégia para manter a mão de obra ocupada (ARAÚJO et al., 2003). Essas características permitiram que a agricultura paulista desenvolvesse lavouras alternativas quando a produção de café entrou em declínio, como as culturas do algodão, da cana-de-açúcar e de citros (ARAÚJO et al., 2003), sendo que essa última pode ser cultivada em áreas de maior declividade, como no leste de São Paulo. O nível tecnológico de São Paulo pode ser explicado pela política pública, à qual se atribuio papel "fundamental e decisivo para transformar a agricultura paulista na mais moderna do país" (FUNDAÇÃO SISTEMA ESTADUAL DE ANÁLISE DE DADOS, 2003, p. 476).

A ocupação do Mato Grosso, por sua vez, ganhou impulso apenas a partir do século XX, com o estímulo à ocupação dos cerrados via políticas de crédito rural para a expansão da agricultura comercial e com as políticas de colonização de terras públicas e incentivos fiscais para investimentos na Amazônia Legal (SICSÚ; LIMA, 2000). A estrutura produtiva do estado de Mato Grosso, segundo Cunha (2006), deve-se, em grande medida, à ação estatal de incentivo à modernização da agropecuária e integração dela a outros setores. Deve-se considerar também o relevo mato-grossense, predominantemente plano, que favoreceu a mecanização, o cultivo de culturas temporárias (soja, milho e algodão, por exemplo). A possibilidade de mecanização da produção, juntamente com os baixos preços da terra e dos custos de produção e a possibilidade de praticar agricultura de grande escala na 
região do cerrado, segundo Sicsú e Lima (2000), foram fatores fundamentais para a expansão da agropecuária. Ademais, destaca-se que o norte do estado do Mato Grosso apresenta ocupação recente baseada na agropecuária, constituindo-se em nova fronteira, o que não ocorre no estado de São Paulo.

Algumas características gerais da produção agropecuária desses estados podem ser observadas agrupando-se o valor da produção agropecuária em produtos animais, grãos e fibras, olerícolas, frutas frescas e produtos vegetais para a indústria, conforme proposto por Tsunechiro et al. (2001) para o estado de São Paulo. Destaca-se que a formação desses grupos não considerou apenas as atividades produtivas analisadas por aqueles autores, mas busca-se, também, a adaptação da metodologia ao estado do Mato Grosso.

A Tabela 3 apresenta a importância de cada um desses grupos sobre o valor total da produção agropecuária de São Paulo e do Mato Grosso nos anos de 1995/96 e 2006. Constata-se haver maior representatividade do valor da produção vegetal para a indústria no Estado de São Paulo e da produção de grãos e fibras no Mato Grosso. Esses resultados foram semelhantes àqueles encontrados pela Fundação Sistema Estadual de Análise de Dados(2003). A importância da produção da cana-de-açúcar no estado de São Paulo sobressai-se, sua participação no valor da produção agropecuária aumentou em 18 pontos percentuais nos dois anos em análise.

Tabela 3 - Percentual do valor da produção agropecuária, por grupos e anos de 1995/1996 e 2006 para São Paulo e Mato Grosso

\begin{tabular}{|c|c|c|c|c|}
\hline \multirow{2}{*}{$\begin{array}{c}\text { Grupos de produtos/estados } \\
\text { e períodos }\end{array}$} & \multicolumn{2}{|c|}{ São Paulo } & \multicolumn{2}{|c|}{ Mato Grosso } \\
\hline & $1995 / 1996$ & 2006 & $1995 / 1996$ & 2006 \\
\hline Olerícolas $^{1}$ & $5 \%$ & $5 \%$ & $1 \%$ & $0,3 \%$ \\
\hline Produtos vegetais para indústria ${ }^{2}$ & $47 \%$ & $58 \%$ & $12 \%$ & $12 \%$ \\
\hline Cana-de-açúcar & $34 \%$ & $52 \%$ & $10 \%$ & $12 \%$ \\
\hline Grãos e fibras ${ }^{3}$ & $9 \%$ & $6 \%$ & $50 \%$ & $63 \%$ \\
\hline Soja em grão & $0,1 \%$ & $0,1 \%$ & $38 \%$ & $36 \%$ \\
\hline Frutas frescas ${ }^{4}$ & $12 \%$ & $6 \%$ & $1 \%$ & $0,2 \%$ \\
\hline Produtos animais & $27,1 \%$ & $25 \%$ & $35,9 \%$ & $25 \%$ \\
\hline Aves e pequenos animais & $10,7 \%$ & $11,7 \%$ & $2,7 \%$ & $1,4 \%$ \\
\hline Animais de grande porte & $15,4 \%$ & $12 \%$ & $32,0 \%$ & $24 \%$ \\
\hline Total & $100 \%$ & $100 \%$ & $100 \%$ & $100 \%$ \\
\hline
\end{tabular}

Fonte: IBGE (1998; 2009).

Nota: (1) olerícolas: abóbora, moranga, jerimum, abobrinha, acelga, agrião, aipo, alcachofra, alface, alho, alho-porró, almeirão, batata-baroa (mandioquinha), batata-doce, batata-inglesa, berinjela, beterraba, brócolis, bucha (esponja vegetal), cebola, cebolinha, cenoura, chicória, chuchu, coentro, couve, couve-flor, erva-doce, ervilha (vagem), espinafre, gengibre, hortelã, inhame, jiló, mandioca (aipim, macaxeira), manjericão, maxixe, mostarda (semente), nabiça, nabo, pepino, pimenta, pimentão, quiabo, rabanete, repolho, rúcula, salsa, taioba, tomate (estaqueado) e vagem (feijão-vagem); (2) produtos vegetais para a indústria: borracha (látex líquido), borracha (látex coagulado), café, cana-de-açúcar, goiaba, laranja e tomate rasteiro (industrial); (3) grãos e fibras: algodão herbáceo, amendoim em casca, arroz em casca, feijão preto em grão, feijão de cor em grão, feijão fradinho em grão, feijão verde, milho em grão, soja em grão, sorgo em grão e trigo em grão; (4) frutas frescas: abacate, abacaxi, ameixa, banana, caqui, carambola, goiaba, jabuticaba, kiwi, laranja, lima, limão, maçã, mamão, manga, maracujá, melancia, melão, morango, nectarina, nêspera, pera, pêssego e uva (mesa). 
Para o estado do Mato Grosso, destacam-se os produtos animais e as produções de grãos e fibras. Não obstante, esses grupos apresentaram comportamentos divergentes. Enquanto a participação dos produtos animais caiu de $36 \%$ para $25 \%$ do valor da produção agropecuária no Mato Grosso de 1995 para 2006, respectivamente; os grãos e fibras aumentaram de 50\% para 63\%, respectivamente. Entretanto, esses dois grupos destacam-se como os principais responsáveis pelo valor da produção agropecuária do Mato Grosso. Essa importância pode ser explicada, em parte, pelo processo de integração entre elas, em que a produção de grãos fornece alimentação a baixo custo para a produção animal, conforme apontado por Sicsú e Lima (2000). Essa justificativa é corroborada por Figueiredo, Barros e Guilhoto (2005), que calcularam o índice de Hirschman-Rasmussen que indicou que o setor de abate de bovinos apresentava a maior interligação para trás, como mercado consumidor de outros setores da economia mato-grossense (desconsiderando o setor de serviços).

Além desses fatores, a pecuária foi incentivada para colonizar novas áreas que apresentam infraestrutura precária, uma vez que os animais podem ser deslocados mais facilmente, inclusive não necessitando de estradas carroçáveis, enquanto a produção de grãos demanda melhor infraestrutura para o escoamento da produção. Nesse sentido, a região de Sinop e Sorriso, que apresenta a maior produção de soja no Mato Grosso, é também aquela com maior concentração de malha viária (ver Figura 1), enquanto o rebanho bovino concentra-se na fronteira norte do estado de Mato Grosso.

Outro ponto de distinção entre os estados de São Paulo e Mato Grosso é a escala de produção. A produção média é maior no estado do Mato Grosso, tomando a área média dos estabelecimentos agropecuários (Tabela 4). A área média dos estabelecimentos agropecuários foi de 431 hectares em 2006, no Mato Grosso, enquanto no estado de São Paulo foi de 74 hectares no mesmo ano. A diferença da área média dos estabelecimentos agropecuários pode ser explicada, além dos aspectos históricos, pelas variáveis de primeira natureza, que incentivaram a formação de monoculturas plantadas em grandes áreas no estado do Mato Grosso. 
Tabela 4 - Indicadores censitários da evolução da agropecuária de São Paulo e Mato Grosso, 1995/1996 e 2006

\begin{tabular}{l|r|r|r|r}
\hline \multirow{2}{*}{ Itens/estados/anos } & \multicolumn{2}{|c|}{ Mato Grosso } & \multicolumn{2}{c}{ São Paulo } \\
\cline { 2 - 4 } & \multicolumn{1}{c|}{$1995 / 1996$} & \multicolumn{1}{c|}{2006} & $1995 / 1996$ & \multicolumn{1}{c}{2006} \\
\hline Número de estabelecimentos & 78.762 & 112.987 & 218.016 & 227.622 \\
Área dos estabelecimentos (ha) & 49.839 .631 & 48.688 .711 & 17.369 .204 & 16.954 .949 \\
Lavouras permanentes (ha) & 169.734 & 408.550 & 1.368 .614 & 1.692 .728 \\
Lavouras temporárias (ha) & 2.782 .011 & 6.018 .182 & 3.887 .554 & 5.293 .118 \\
Pastagens naturais (ha) & 6.189 .573 & 4.404 .283 & 2.006 .431 & 2.900 .859 \\
Pastagens plantadas (ha) & 15.262 .488 & 17.658 .375 & 7.055 .823 & 4.075 .380 \\
Matas naturais (ha) & 21.475 .765 & 19.106 .923 & 1.352 .379 & 1.917 .285 \\
Matas plantadas (ha) & 67.829 & 69.714 & 597.000 & 372.563 \\
Área média dos estabelecimentos (ha) & 633 & 431 & 80 & 74 \\
Área utilizada (ha) & 28.296 .037 & 29.512 .074 & 15.419 .825 & 14.665 .101 \\
Pessoal ocupado (unidades) & 326.767 & 358.336 & 914.954 & 910.848 \\
Tratores (unidades) & 32.752 & 42.330 & 170.573 & 145.346 \\
Bovinos (cabeças) & 14.438 .135 & 20.666 .147 & 12.306 .790 & 10.506 .430 \\
\hline
\end{tabular}

Fonte: Instituto Brasileiro de Geografia e Estatística (1998; 2009).

Nota 1: corresponde à área total dos estabelecimentos, excluindo a área coberta com matas nativas e plantadas.

Entretanto, há uma tendência de aumento do número de estabelecimentos e redução da área total (Tabela 4), tanto no Mato Grosso como em São Paulo, entre 1995/1996 e 2006. A redução da área total dos estabelecimentos pode ser explicada pelo aumento da área urbana das cidades e pela criação de unidades de conservação e demarcação de terras indígenas. Após 1995, essas áreas incorporaram 24,655 mil e 2,806 milhões de hectares nos estados de São Paulo e Mato Grosso, respectivamente (INSTITUTO BRASILEIRO DE GEOGRAFIA E ESTATÍSTICA, 2009). A redução do tamanho médio dos estabelecimentos pode ser explicada tanto pela redução da área total como pelo aumento do número dos estabelecimentos agropecuários.

Os dados apresentados para número de bovinos para o estado do Mato Grosso e sobre a área ocupada com lavouras temporárias indicam que ambos apresentaram crescimento no período de 1995/1996 a 2006. Dessa forma, apesar dos produtos animais terem reduzido sua contribuição percentual para o valor da produção agropecuária no período analisado (Tabela 3), os dados indicam que a razão para essa queda não é necessariamente a redução da atividade pecuária no estado, mas, sim, o maior crescimento do grupo de grãos e fibras, muito embora estejam sendo 
considerados apenas os bovinos (os principais responsáveis pelo valor da produção animal no Mato Grosso).

Os indicadores para uso de tratores e pessoal ocupado são substancialmente maiores para São Paulo do que para Mato Grosso, mesmo esse último tendo maior área agropecuária, aproximadamente quase três vezes maior que São Paulo. A maior utilização de mão de obra e tratores no estado de São Paulo, quando comparada ao Mato Grosso, pode ser explicada, em parte, pelas principais atividades agropecuárias em cada um desses estados. O estado do Mato Grosso apresenta uma proporção maior da área ocupada com pastagens destinadas à produção animal, enquanto São Paulo apresentou maior área ocupada com culturas temporárias. Ademais, pode ser inferido que o estado do Mato Grosso apresenta tratores e implementos de maior potência, o que pode explicar a diferença no número de tratores entre os dois estados. Em 2006, Mato Grosso possuía aproximadamente 20 mil e 24 mil tratores de menos de $100 \mathrm{CV}$ e de $100 \mathrm{CV}$ ou acima, respectivamente, enquanto São Paulo possuía aproximadamente 107 mil e 38 mil tratores, respectivamente, segundo dados do Censo Agropecuário de 2006. Portanto, em São Paulo predominam tratores de menor potência e o inverso ocorre no Mato Grosso.

A distribuição dos tipos de culturas na ocupação da área de cada estado pode ser explicada pela infraestrutura de cada estado. As culturas temporárias demandam melhor infraestrutura para o escoamento da produção, ao passo que os animais podem ser deslocados mesmo não havendo estradas carroçáveis. A maior proporção das culturas permanentes em São Paulo do que no Mato Grosso também pode ser explicada pelo relevo. Áreas com declividade acima de $8 \%$ limitam a mecanização e são mais adequadas ao cultivo de culturas permanentes, enquanto o estado do Mato Grosso apresenta relevo predominantemente plano, sendo adequado para o cultivo de culturas temporárias.

A maior mecanização e inovações tecnológicas juntamente com a introdução de novos produtos e as mudanças na legislação trabalhista contribuíram para a queda do número de pessoas empregadas na produção agropecuária (FIGUEIREDO; BARROS; GUILHOTO, 2005), o que ocorreu no estado de São Paulo entre 1995 e 2006 (ver Tabela 4). Somando-se a esses fatores, pode ter contribuído para a queda do uso de mão de obra no período estudado no estado de São Paulo a redução da utilização do fogo para o corte da cana-de-açúcar e a expansão da mecanização nessa cultura (STADUTO; SHIKIDA; BACHA; 2004). A redução da utilização da queima deve-se à legislação paulista (Lei Estadual no 11.241, de 19 de setembro de 2002) que estipulou cronograma de redução da área em que a palha da cana pode ser queimada, devendo essa queima ser extinta em 2021 e em 2031 para áreas 
mecanizáveis e não mecanizáveis, respectivamente. A importância da cultura da cana-de-açúcar no estado pode ser percebida quando se considera que a área colhida com cana-de-açúcar ocupou $18 \%$ da área total dos estabelecimentos agropecuários em 2006 (IBGE, 2006 ), gerando 52\% do valor da produção agropecuária em 2006 (Tabela 3 ).

Por outro lado, o efeito das inovações tecnológicas não apresentaria grande importância na utilização de mão de obra no estado do Mato Grosso, uma vez que nesse estado a produção de grãos apresenta maior importância e - segundo Staduto, Shikida e Bacha (2004) - o setor de grãos já apresentava elevado uso da mecanização. Isto explica o menor uso de mão de obra na agropecuária do Mato Grosso em relação à de São Paulo (ver Tabela 4).

Entre os anos de 1995 e 2006 também se destacam a expansão do rebanho bovino no estado de Mato Grosso e seu baixo padrão tecnológico, conforme pode-se observar em dados da Fundação Sistema Estadual de Análise de Dados (200-). Ademais, o elevado número de cabeças de bovinos no Mato Grosso pode ser explicado pelo gado ser utilizado como forma de apropriação e legitimação da posse da terra, conforme destacado por Bonjour, Figueiredo e Marta (2008), além das condições precárias de infraestrutura para transporte e armazenamento de grãos nas áreas de fronteira agrícola (norte do Mato Grosso).

Analisando a utilização das terras nos estabelecimentos agropecuários do Mato Grosso e de São Paulo (Tabela 4), destaca-se a baixa utilização das terras no Mato Grosso, com matas plantadas e lavouras permanentes, enquanto em São Paulo há menor heterogeneidade da distribuição da área utilizada, que se concentra em pastagens plantadas e lavouras temporárias.

A área ocupada nos dois estados indica a predominância da porção utilizada com pastagens plantadas e lavouras temporárias e a maior importância de lavouras temporárias em relação às culturas permanentes. Essa utilização era esperada e indica a importância da produção de grãos (no Mato Grosso) e de cana-de-açúcar (em São Paulo) e de carnes baseada em pastagens. Por sua vez, a importância da área ocupada com lavouras temporárias aumentou em ambos os estados entre 1995/1996 e 2006, enquanto a área com pastagens plantadas aumentou sua importância no Mato Grosso e reduziu-a em São Paulo. Segundo Espindola et al. (2011), o aumento da área com pastagens e culturas temporárias (Tabelas 3 e 4) é resultado da conversão de áreas de matas para a criação em larga escala de bovinos e, posteriormente, á conversão da área para o plantio de soja. Destaca-se que o cultivo da soja é baseado em grandes investimentos por parte dos produtores e pela pesquisa e melhoramento genético das variedades cultivadas. 
O aumento relativo da área com pastagens plantadas e a redução relativa na área de pastagens naturais no Mato Grosso podem ser explicados pelo aumento da produtividade da pecuária (Tabela 5). O número de cabeças de bovinos por hectare de pastagem aumentou de 0,67 para 0,94 no Mato Grosso e de 1,36 para 1,51 em São Paulo entre 1995/1996 e 2006, respectivamente. Segundo Bonjour, Figueiredo e Marta (2008), esse aumento para o Mato Grosso pode ser atribuído ao aumento da eficiência dos produtores e ganhos de produtividade com a utilização do confinamento.

Tabela 5 - Evolução da utilização da área no Mato Grosso e São Paulo, em percentual, anos de 1995/1996 e 2006

\begin{tabular}{l|c|c|c|c}
\hline \multirow{2}{*}{\multicolumn{1}{c|}{ Itens/estados/anos }} & \multicolumn{2}{|c|}{ Mato Grosso } & \multicolumn{2}{c}{ São Paulo } \\
\cline { 2 - 5 } & 1995 & 2006 & 1995 & 2006 \\
\hline Área lavoura permanente /AE & $0,3 \%$ & $0,8 \%$ & $7,9 \%$ & $10,0 \%$ \\
Área lavouras temporária /AE & $\mathbf{5 , 6 \%}$ & $\mathbf{1 2 , 4 \%}$ & $\mathbf{2 2 , 4 \%}$ & $\mathbf{3 1 , 2 \%}$ \\
Área pastagens naturais /AE & $12,4 \%$ & $9,0 \%$ & $11,6 \%$ & $17,1 \%$ \\
Área pastagens plantadas /AE & $\mathbf{3 0 , 6 \%}$ & $\mathbf{3 6 , 3 \%}$ & $\mathbf{4 0 , 6 \%}$ & $\mathbf{2 4 , 0 \%}$ \\
Área matas naturais/AE & $\mathbf{4 3 , 1 \%}$ & $\mathbf{3 9 , 2} \%$ & $7,8 \%$ & $11,3 \%$ \\
Área matas plantadas /AE & $0,1 \%$ & $0,1 \%$ & $3,4 \%$ & $2,2 \%$ \\
Áreas inaproveitáveis/AE & $7,9 \%$ & $2,2 \%$ & $6,3 \%$ & $4,2 \%$ \\
Total & $100 \%$ & $100 \%$ & $100 \%$ & $100 \%$ \\
\hline
\end{tabular}

Fonte: Instituto Brasileiro de Geografia e Estatística (1998; 2009).

Nota: $\mathrm{AE}$ - área dos estabelecimentos.

Chama a atenção os percentuais da área dos estabelecimentos ocupada com matas naturais, muito abaixo do legalmente estabelecido pelo Código Florestal, considerando apenas a reserva legal, embora o estado de São Paulo tenha apresentado uma pequena elevação no percentual da área ocupada pelas matas naturais dentro dos estabelecimentos agropecuários. O estado de Mato Grosso está inserido na Amazônia Legal, sendo permitido o corte raso de apenas 20\% na área da Floresta Amazônica e 65\% nas áreas de Cerrado. Na região do Pantanal não é permitido o desmatamento. Dessa forma, a área com florestas destinadas apenas à reserva legal seria equivalente a aproximadamente $63,5 \%$ da área total dos estabelecimentos agropecuários do Mato Grosso, enquanto o efetivamente observado foi de 39,2\% em 2006 (Tabela 5). No estado de São Paulo, a área mínima estabelecida para a reserva legal é de $20 \%$ da área total, entretanto, em 2006 a área ocupada 
com florestas naturais totalizava $11,3 \%$ da área total dos estabelecimentos agropecuários paulistas.

Destaca-se também que o estado do Mato Grosso apresentou uma substancial melhora na produtividade da mão de obra (medida pela receita gerada por pessoa empregada ao ano), que aumentou de $R \$ 14.709,44$ para $R \$ 29.325,96$ (a preços de dezembro de 2006), como se pode conferir na Tabela 6. Observa-se também que esse estado aumentou a relação receita/insumos produtivos na grande maioria desses indicadores, exceção à relação receita/defensivos. Ademais, os dados indicam o aumento no uso dos insumos (terra, mão de obra e defensivos).

Tabela 6 - Comparativo do uso de insumos e receitas para São Paulo e Mato Grosso, anos de $1995 / 1996$ e 2006

\begin{tabular}{l|r|r|r|r}
\hline \multirow{2}{*}{\multicolumn{1}{c|}{ Itens/estados/anos }} & \multicolumn{2}{c|}{ Mato Grosso } & \multicolumn{2}{c}{ São Paulo } \\
\cline { 2 - 5 } & $1995 / 1996$ & 2006 & $1995 / 1996$ & \multicolumn{1}{c}{2006} \\
\hline Pessoas ocupadas/AE (em mil ha) & 6,56 & 7,36 & 52,7 & 53,7 \\
Área utilizada (ha)/homem & 87 & 82 & 17 & 16 \\
Bovinos (cab.)/AE & 0,29 & 0,42 & 0,71 & 0,62 \\
Bovinos (cab.)/pastagens (ha) & 0,67 & 0,94 & 1,36 & 1,51 \\
Tratores/AE (mil ha) & 0,66 & 0,87 & 9,82 & 8,57 \\
Financiamento (em R $\$$ de 2006)/AE & 10,41 & 51,18 & 111,76 & 228,81 \\
Investimento (em R\$ de 2006)/AE & 23,08 & 25,93 & 162,32 & 218,44 \\
Defensivos (em R $\$$ de 2006)/área utilizada (ha) & 92,05 & 292,88 & 451,66 & 664,46 \\
Defensivos (em R $\$$ de 2006)/AE & 45,07 & 171,37 & 372,33 & 547,17 \\
Receitas (em R $\$$ de 2006)/área utilizada (ha) & 196,96 & 368,86 & $1.968,60$ & $1.806,08$ \\
Receitas (em R $\$$ de 2006)/AE & 96,44 & 215,83 & $1.622,83$ & $1.487,27$ \\
Receitas (em R $\$$ de 2006)/defensivos (R\$ de 2006) & 2,14 & 1,26 & 4,36 & 2,72 \\
Receitas (em R $\$$ de 2006)/trator & 146.756 & 248.253 & 165.251 & 173.494 \\
Receitas (em R $\$$ de 2006)/PO & $14.709,44$ & $29.325,96$ & $30.807,34$ & $27.684,81$ \\
\hline
\end{tabular}

Fonte: Instituto Brasileiro de Geografia e Estatística (1998; 2009).

Nota: 1 ha - hectare; AE - área dos estabelecimentos, em ha; PO - pessoas ocupadas, em unidades; cab. - cabeças.

$2 \mathrm{~A}$ área utilizada corresponde à área total dos estabelecimentos excluindo a área coberta com matas nativas e plantadas.

3 As variáveis Financiamentos e Investimento foram deflacionados pelo Índice Geral de Preços - Disponibilidade Interna para dezembro de 2006.

4 A variável Defensivos corresponde ao somatório das despesas efetuadas pelos estabelecimentos em adubos, corretivos do solo, sementes e mudas, agrotóxicos, medicamentos para animais, sal e rações (industrializados ou não industrializados), energia elétrica e combustíveis, em reais de dezembro de 2006, deflacionado pelo índice de preços pagos pelos produtores, por estado.

5 As receitas foram deflacionadas usando o Índice de Preços Recebidos pelos Agricultores, para dezembro de 2006.

Entretanto, há uma diferença substancial na geração de receita por hectare entre os dois estados analisados, sendo a receita por hectare maior no estado de São Paulo do que no Mato Grosso. Esse resultado pode ser relacionado ao custo 
da terra em cada estado: em dezembro de 2006, um hectare de terra para lavoura custava no Mato Grosso e São Paulo, respectivamente, $R \$ 4.485,62$ e R\$ 9.940,44 e um um hectare de terra para pastagem custava $R \$ 1.819,00$ e $R \$ 7.185,27$, respectivamente (FUNDAÇÃO GETÚLIO VARGAS, 200-).

A produtividade parcial de alguns fatores na agropecuária do estado de São Paulo apresentou comportamento diferente quando comparado ao Mato Grosso. Apesar de o primeiro apresentar maiores receitas por pessoa ocupada, por trator, por área e por defensivos quando comparadas ao segundo, São Paulo apresentou queda em quase todos os indicadores para a geração da receita por insumo entre 1995/1996 e 2006.

\section{Conclusões}

Este artigo utilizou alguns conceitos da nova geografia econômica para analisar a evolução da agropecuária em São Paulo e no Mato Grosso entre os anos de 1995 e 2006. Focou-se especificamente nos conceitos de variáveis de primeira e segunda natureza, procurando-se analisar como elas estimularam ou restringiram o crescimento da agropecuária nesses estados.

Apesar de as variáveis de segunda natureza serem menos vantajosas à expansão da agropecuária no Mato Grosso do que em São Paulo, a melhoria quantitativa e qualitativa dos índices no primeiro estado, associada à ampla disponibilidade de terras em Mato Grosso, tem permitido o aumento da produção agropecuária acima de São Paulo, sendo que ambos desenvolvem agropecuárias com estruturas distintas. Os indicadores parciais sugerem melhora da produtividade parcial da terra e do trabalho no Mato Grosso a ritmo maior do que em São Paulo. Isso, no entanto, não indica que a eficiência técnica em Mato Grosso é maior do que em São Paulo, pois a análise realizada no presente artigo não contempla todas as variáveis consideradas no cálculo dessa eficiência.

Os resultados apresentados no artigo são importantes para evidenciar como restrições ambientais (variáveis de segunda natureza) podem ser compensadas por condições edafoclimáticas (variáveis de primeira natureza) e disponibilidade de tecnologia, permitindo o crescimento da agropecuária, como no caso do Mato Grosso. 


\title{
The evolution of agriculture in the states of Sao Paulo and Mato Grosso from 1995 through 2006
}

\begin{abstract}
Based on some New Economic Geography concepts, this paper assesses the constraints and advantages that first and second nature variables bring to stimulate and / or restrict agricultural production in the states of São Paulo and Mato Grosso. Despite some second nature variables (such as forest legislation) are potentially more restrictive to Mato Grosso's agriculture and others are less supplied in this state than in Sao Paulo (such as banking, education and research services), there were significant improvement in these variables. The later, together with the vast availability of land in Mato Grosso (with good topography and varied climate) more than offset its lower fertility. This explains why some partial productivity indicators show higher increase in Mato Grosso's agriculture than in São Paulo's agriculture between 1995 and 2006. Nevertheless, we can not say that agriculture's technical efficiency in Mato Grosso is higher than in São Paulo, because not all variables were considered into our analyses.
\end{abstract}

Keywords: Agriculture. Mato Grosso. Sao Paulo. Evolution.

\section{La evolución de la agricultura en los estados de Sao Paulo y Mato Grosso desde 1995 hasta 2006}

\section{Resumen}

Con base en algunos conceptos de la Nueva Geografía Económica, este documento evalúa las limitaciones y ventajas que las variables de lo primero y de lo segundo naturaleza aportan a estimular y / o limitar la producción agrícola en los estados de Sao Paulo y Mato Grosso. A pesar de algunas variables de segunda naturaleza (tales como la legislación forestal) son potencialmente más restrictiva para la agricultura del Mato Grosso y otros son menos ofertadas en este estado que en Sao Paulo (tales como servicios bancarios, de educación y de investigación), hubo una mejora significativa en estos variables. Las ultimas, junto con la gran disponibilidad de tierras en Mato Grosso (con buena topografía y clima variado) más que compensar su menor fertilidad. Esto explica por qué algunos indicadores de productividad parcial muestran mayor aumento en la agricultura de Mato Grosso que en la agricultura de São Paulo entre los años de 1995 y 2006. Sin embargo, no podemos decir que la eficiencia técnica en la agricultura de Mato Grosso es mayor que en San Pablo, porque no todas las variables fueron consideradas en nuestra análisis.

Palabras clave: Agricultura. Mato Grosso. Sao Paulo. La evolución. 


\section{Notas}

1 Foram considerados caroço de algodão, amendoim (1 $1^{\mathrm{a}}$ e $2^{\mathrm{a}}$ safras), arroz, aveia, canola, centeio, cevada, feijão (1 $1^{a}, 2^{a}$ e $3^{\text {a }}$ safras), girassol, mamona, milho (1 $1^{\underline{a}}$ e $2^{\underline{a}}$ safras), soja, sorgo, trigo e triticale.

2 Considerando apenas a produção agropecuária, essa respondeu por $22 \%$ do PIB estadual em 2009 (INSTITUTO DE PESQUISA ECONÔMICA APLICADA, 200-).

\section{Referências}

AGÊNCIA NACIONAL DE TRANSPORTES TERRESTRES. Anuário Estatístico dos Transportes Terrestres - 2009. Disponível em: <http://www.antt.gov.br/index.php/content/view/10868/ Ano_2009.html>. Acesso em: 20 jul. 2014.

ARAÚJO, P. F. C. et al. Contribuição da FAPESP à agricultura do estado de São Paulo. São Paulo: FAPESP, 2003. 176 p. Relatório final do projeto contribuição da Fapesp à agricultura do Estado de São Paulo.

BACHA, C. J. C. Economia e política agrícola no Brasil. 2. ed. São Paulo: Atlas, 2012. 264 p.

BONJOUR, S. C. M.; FIGUEIREDO, A. M. R.; MARTA, J. M. C. A pecuária de corte no estado de Mato Grosso. In: CONGRESSO DA SOCIEDADE BRASILEIRA DE ECONOMIA, ADMINISTRAÇÃO E SOCIOLOGIA RURAL, 2008, Cuiabá. Anais... Cuiabá: SOBER, 2008. p. 1-21.

BRASIL. Banco Central do Brasil. Anuário estatístico do crédito rural. 2012. Disponível em: <http://www.bcb.gov.br/?RELRURAL>. Acesso em: 6 ago. 2014.

. Banco Central do Brasil. Relação de agências e postos bancários. Transferência de arquivos. 2014. Disponível em: <http://www.bcb.gov.br/?RELAGPAB>. Acesso em: 6 ago 2014 .

BRASIL. Ministério do Meio Ambiente. Monitoramento do desmatamento nos biomas brasileiros por satélite: monitoramento do bioma Pantanal, 2002 a 2008. Brasília: Centro de Informação, Documentação Ambiental e Editoração Luís Eduardo Magalhães, 2010. 30 p.

Lei $\mathrm{n}^{\circ}$ 12.727/2012, de 17 de outubro de 2012. Altera a Lei $\mathrm{n}^{\circ} 12.651$, de 25 de maio de 2012, que dispõe sobre a proteção da vegetação nativa; altera as leis $\mathrm{n}^{\circ} 6.938$, de 31 de agosto de 1981, 9.393, de 19 de dezembro de 1996, e 11.428, de 22 de dezembro de 2006; e revoga as leis $\mathrm{n}^{\mathrm{o}}$ 4.771, de 15 de setembro de 1965, e 7.754, de 14 de abril de 1989, a Medida Provisória no 2.16667, de 24 de agosto de 2001, o item 22 do inciso II do art. 167 da Lei $\mathrm{n}^{\circ} 6.015$, de 31 de dezembro de 1973, e o $\S 2^{\circ}$ do art. 40 da Lei n⿳ 12.651, de 25 de maio de 2012. Diário Oficial da União. Brasília, p. 1, col. 1, 18 out. 2012 b.

Ministério da Agricultura, Pecuária e Abastecimento. Estatísticas e dados básicos de economia agrícola. Brasília, 2014. 54p.

. Ministério dos Transportes. Plano Nacional de Logística e Transportes. 2008. Disponível em: <http://mapas.mma.gov.br/i3geo/datadownload.htm>. Acesso em: 22 mar. 2015.

CANO, W. et al. (Org.) Economia paulista: dinâmica socioeconômica entre 1980 e 2005. São Paulo: Alinea, 2007. 574 p.

CASTRO, C. N. A agropecuária na Região Centro-Oeste: limitações ao desenvolvimento e desafios futuros. Rio de Janeiro: IPEA, 2014. 41 p. Texto para discussão, 1.923. 
COMPANHIA DOCAS DO ESTADO DE SÃO PAULO. Mensário estatístico do Porto de Santos. dez. 2015. 32 p. Disponível em: <http://201.33.127.41/DocPublico/estmen_CPT/2015/estmen-2015-12.pdf>. Acesso em: 24 fev. 2016.

COMPANHIA NACIONAL DE ABASTECIMENTO. Acompanhamento da safra brasileira grãos. Safra 2015/16, Brasília, v. 3, n 5, fev. 2016a. Disponível em<http://www.conab.gov.br/ OlalaCMS/uploads/arquivos/16_02_04_11_21_34_boletim_graos_fevereiro_2016_ok.pdf>. Acesso em: 24 fev. 2016.

Capacidade estática. 2016b. Disponível em: <http://sisdep.conab.gov.br/capacidadeestatica//arquivos/relatorio_QA7owm.html.pdf>. Acesso em: 24 fev. 2016.

CUNHA, J. M. P. D. Dinâmica migratória e o processo de ocupação do Centro-Oeste brasileiro: o caso de Mato Grosso. Revista Brasileira de Estudos de População, Campinas, v. 23, p. 87-107, jan./jun. 2006.

DEPARTAMENTO NACIONAL DE INFRAESTRUTURAS DE TRANSPORTES. Relatório dos levantamentos funcionais das rodovias federais: Mato Grosso. Brasília: DNIT/SGP, 2013a. 32 p. Disponível em: <http://www.dnit.gov.br/planejamento-e-pesquisa/planejamento/evolucaoda-malha-rodoviaria/relatorio-sgp-2012-2013-mt.pdf>. Acesso em: 21 jul. 2014.

Relatório dos levantamentos funcionais das rodovias federais: São Paulo. Brasília: DNIT/SGP, 2013b. 32 p. Disponível em: <http://www.dnit.gov.br/planejamento-e-pesquisa/planejamento/evolucao-da-malha-rodoviaria/relatorio-sgp-2012-2013-sp.pdf>. Acesso em: 21 jul. 2014. ESPINDOLA, G. M. de et al. Agricultural land use dynamics in the Brazilian Amazon based on remote sensingmand census data. Applied Geography, Oxford, v. 32, n. 2, p. 240 252, Mar. 2011. FERREIRA, J. C. V. Mato Grosso e seus municípios. Cuiabá: Secretaria de Estado de Educação, 2001. 64 p.

FIGUEIREDO, M. G.; BARROS, A. L. M.; GUILHOTO, J. J. M. Relação econômica dos setores agrícolas do Estado do Mato Grosso com os demais setores pertencentes tanto ao Estado quanto ao restante do Brasil. Revista de Economia e Sociologia Rural, Piracicaba, v. 43, n. 3, p. 557-575, jul./set. 2005.

FUJITA, M.; KRUGMAN, P. The new economic geography: past, present and the future. Papers in Regional Science, Hoboken, v. 83, n. 1, p. 139-164, Jan. 2004.

FUNDAÇÃO GETÚLIO VARGAS. Índice Geral de Preços - Disponibilidade Interna. 2014. Disponível em: <http://www14.fgv.br/novo_fgvdados>. Acesso em: 26 fev. 2014.

FUNDAÇÃO SISTEMA ESTADUAL DE ANÁLISE DE DADOS. Estudo de mercado de trabalho como subsídio para a reforma da educação profissional no estado de São Paulo. São Paulo: SEADE, 2003. $530 \mathrm{p}$.

Preços Agropecuários. [200-]. Disponível em: <http://www.antigofgvdados.fgv.br/chart/ fgvdados_14_9_2016_28_31.htm>. Acesso em: 26 fev. 2014b.

Pesquisa da Atividade Econômica Regional: Mato Grosso - agropecuária. [200-]. Disponível em: <http://portal.mec.gov.br/setec/arquivos/pdf/agropec_mt.pdf>. Acesso em: 12 mar 2014.

INSTITUTO BRASILEIRO DE GEOGRAFIA E ESTATÍSTICA. @Cidades. 2014. Disponível em: <http://www.cidades.ibge.gov.br/download/mapa_e_municipios.php?lang=\&uf=mt>. Acesso em: 2 fev. 2014.

Atlas geográfico escolar. 6. ed. Rio de Janeiro, 2012. 218 p. 
. Censo Agropecuário 1995 - 1996: Brasil. Rio de Janeiro: IBGE, 1998. p. 1-358.

. Censo agropecuário 1995/1996. 1998. Disponível em <http://www.sidra.ibge.gov.br/bda/ pesquisas/ca/default1996.asp? $\mathrm{z}=\mathrm{p} \& \mathrm{o}=2 \& \mathrm{i}=\mathrm{P}>$. Acesso em: $27 \mathrm{fev} .2014$.

. Censo Agropecuário 2006: Brasil, grandes regiões e unidades da federação. Rio de Janeiro: IBGE, 2009. p. 1-777.

. Censo Agropecuário 2006. Disponível em <http://www.sidra.ibge.gov.br/bda/pesquisas/ ca/default.asp?z=p\&o=2>. Acesso em: 27 fev. 2014.

. Mapas de biomas e de vegetação. 2004. Disponível em: <ftp://ftp.ibge.gov.br/Cartas_e_ Mapas/Mapas_Murais/biomas_pdf.zip>. Acesso em: 10 maio 2014.

INSTITUTO DE PESQUISA ECONÔMICA APLICADA. Contas Nacionais. [200-]. Disponível em: <http://www.ipeadata.gov.br>. Acesso em: 24 fev. 2014.

INSTITUTO NACIONAL DE ESTUDOS E PESQUISAS EDUCACIONAIS ANÍSIO TEIXEIRA. Microdados Censo da Educação Superior. 2008. Disponível em: <http://download.inep.gov.br/microdados/microdados_educacao_superior_2006.zip>. Acesso em: 15 jul. 2014.

KRUGMAN, P. What's new about the new economic geography? Oxford Review of Economic Policy, Oxford, v. 14, n. 2, p. 7-17, June 1998.

MANZATTO, C. V. et al. Zoneamento agroecológico da cana-de-açúcar. Rio de Janeiro: Embrapa Solos, 2009. 55 p.

MARTIN, N. B. Regionalização da agricultura paulista. São Paulo em Perspectiva, São Paulo, v. 7, n. 3, p. 51-59, jul./set. 1993.

MATO GROSSO. Lei no ${ }^{\circ}$ 8.830, de 21 de janeiro de 2008. Dispõe sobre a Política Estadual de Gestão e Proteção à Bacia do Alto Paraguai. Diário Oficial, Cuiabá, 21 jan. 2008. p. 3-5.

MENDES, J. T. G.; PADILHA JÚNIOR, J. B. Agronegócio: uma abordagem econômica. São Paulo: Pearson Prentice Hall, 2007. 369 p.

NICHOLLS, W.H. A fronteira agricola na história recente do Brasil: O estado do Paraná, 192065. Revista Brasileira de Economia, Rio de Janeiro, v. 24, n. 4, p. 113-191, out./dez. 1970.

PEREIRA, B. D. Mato Grosso: princípais eixos viários e a modernização da agricultura. Cuiabá: EdUFMT, 2007. 55 p.

SCHMUTZLER, A. The new economic geography. Journal of Economic Surveys, Oxford, v. 13, n. 4, p. 355-379, Sept. 1999.

SICSÚ, A. B.; LIMA, J. P. R. Fronteiras agrícolas no Brasil: a lógica de sua ocupação recente. Nova Economia, Belo Horizonte, v. 10, n. 1, p. 109-138, jul. 2000.

SILVA, R. R.; BACHA, C. J. C. Acessibilidade e aglomerações na Região Norte do Brasil sob o enfoque da nova geografia econômica. Nova Economia, Belo Horizonte, v. 24, n. 1, p. 169-190, jan./abr. 2014.

STADUTO, J. A. R.; SHIKIDA, P. F. A.; BACHA, C. J. C. Alteração na composição da mão-deobra assalariada na agropecuária brasileira. Revista de Economia Agrícola, São Paulo, v. 51, n. 2, p. 57-70, jul./dez. 2004.

TSUNECHIRO, A. et al. Valor da produção agropecuária do estado de São Paulo, por escritório de desenvolvimento rural e por região administrativa, 1995-2000. Informações Econômicas, São Paulo, v. 31, n. 7, p. 17-41, jul. 2001. 